\title{
LA EXCLUSIÓN DE LA PREVENCIÓN DE RIESGOS LABORALES DE LA RELACIÓN LABORAL ESPECIAL DEL TRABAJO DOMÉSTICO: ANÁLISIS CRÍTICO DE LAS POSIBLES RAZONES
}

\section{Excluding occupational hazard prevention from the special employment} relationship of domestic work: critical analysis of possible reasons

\section{Concepción SANZ Sáez*}

Universidad de Castilla La Mancha, España

\section{RESUMEN}

$\mathrm{Al}$ igual que ocurre con el resto de las personas trabajadoras, las trabajadoras de esta relación laboral especial del trabajo doméstico están expuestas a ciertos riesgos laborales propios de la actividad que desempeńan. En este artículo se analiza de forma crítica la esfera subjetiva de la exclusión expresa de la Ley de Prevención en la relación laboral especial de servicio del hogar familiar.

Palabras clave: trabajo doméstico, seguridad y salud, exclusión, negociación colectiva, género.

\section{ABSTRACT}

As with the rest of the workers, the workers in this special labor relationship of domestic work are exposed to certain occupational risks inherent to the activity they perform. This article critically analyzes the subjective sphere of the express exclusion of the Prevention Law in the special employment relationship of family home service.

Keywords: domestic work, health and safety, exclusion, collective bargaining, gender.

\footnotetext{
* Correspondencia a: Concepción Sanz Sáez. Rda. Del Parque, 28 bajo A, Ciudad Real, (Castilla La Mancha), España. - concepcion.sanz@ucim.es - https://orcid.org/0000-0002-9783-9272

Cómo citar: Sanz Sáez, Concepción. (2020). «La exclusión de la prevención de riesgos laborales de la relación laboral especial del trabajo doméstico: análisis crítico de las posibles razones»; Lan Harremanak, 44, 79-102. (https://doi.org/10.1387/lan-harremanak.22126).

Recibido: 15 octubre, 2020; aceptado: 12 noviembre, 2020.

ISSN 1575-7048 - eISSN 2444-5819 / (C) 2020 UPV/EHU
} 


\section{Introducción}

Que el empleo doméstico es un trabajo precario, con un alto grado de feminización y con peligro de encontrarse frente a escenarios de explotación no es una novedad. Y es que el trabajo doméstico socialmente ha estado desde siempre poco considerado y, en consecuencia, con «una menor protección que el trabajo en otros ámbitos de actividad» (Cabeza, 2015: 99 y ss.).

Los peligros en las actividades a las que se enfrentan las trabajadoras domésticas son más serios de lo que se cree pues estas personas ejecutan todo tipo de tareas en el hogar, con lo que están expuestos a distintos riesgos laborales.

Al mismo tiempo, debemos tener en cuenta que el lugar donde se efectúa el trabajo es el domicilio familiar que puede ser su residencia habitual u ocasional, como pueden ser entre otras, las segundas residencias, por lo que los riesgos pueden ser distintos.

Los riesgos laborales en estos domicilios particulares, al considerarse actividades especiales y no ser entornos controlados, ni reglados como lugares de trabajo, no tienen que pasar por los procedimientos de evaluación de riesgos o la autorización de funcionamiento como sucede con los entornos laborales generales.

Asimismo, por el hecho de que la relación laboral se desarrolle en el domicilio de la parte empleadora, se ocasiona un aislamiento e invisibilidad de la parte empleada que obstaculiza considerablemente el control de la normativa laboral por la Inspección de Trabajo. Y por esta misma razón, se dificulta extraordinariamente la acción sindical lo que unido a una tradicional despreocupación de los sindicatos respecto a estos trabajadores/as y a la ausencia total de negociación colectiva, termina por complicar en extremo el contexto en que se desenvuelve esta prestación de servicios (Lousada, 2018: 152-187).

Ante esta situación, quiere aclararse que, a lo largo de este trabajo, la consideración al servicio doméstico se hará atendiendo a una forma de lenguaje no sexista, ya que, aunque minoritariamente, también hay hombres dedicados a esta relación laboral. En consideración a lo expuesto, mi planteamiento tiene por objeto un estudio jurídico de riesgos laborares en el trabajo doméstico, sea quien fuere quien lo realice ${ }^{1}$. No obstante, en este estudio me he centrado más en el colectivo de las mujeres por el importante peso que éstas tienen en la acti-

\footnotetext{
1 Según los datos disponibles del Instituto Nacional de Estadística (INE), correspondientes al último trimestre de 2019, en Espańa hay 580.600 empleadas del hogar. Es un colectivo feminizado, ya que, según los datos de la Encuesta de Población Activa del INE, el 86,4\% son mujeres (501.800 trabajadoras domésticas frente a 78.800 trabajadores domésticos).
} 
vidad del servicio doméstico y por la situación de irregularidad laboral tan acusada que les afecta en dicha relación laboral ${ }^{2}$.

Dicho esto, y partiendo de la base que no parece posible que esto siga sucediendo en la actualidad, recordemos que la obligación de los poderes públicos de velar por la seguridad e higiene en el trabajo (Cardenal y Cardenal, 2002: 213274), principio rector de la política social, artículo 40 de la Constitución Espańola (en adelante CE), no tiene ningún desarrollo en el trabajo doméstico, tal es así, que la propia Ley 31/1995, de 8 de noviembre, de Prevención de Riesgos Laborales (en adelante LPRL), declara en su artículo 3. ${ }^{\circ}$.4.que la norma no se aplica a la relación laboral especial al servicio del hogar familiar, con una exclusión absoluta.

Por otra parte, quiere destacarse la fuerte impronta de individualidad en la relación laboral en cuestión al ser un trabajo de muy baja sindicación, siendo éste un factor que justifica su poca capacidad de reivindicación y presión, siempre unido a la inexistencia de asociaciones empresariales específicas (Nieto, 2019: 405).En este sentido se debe recordar que, no tienen convenio propio, no cuentan en las organizaciones sindicales con servicios específicos de atención y asesoramiento para esta relación laboral especial, ni tampoco existe, como digo, patronal con la que negociar (Sanz, 2019: 5). El hecho de que estas mujeres no tengan un centro de trabajo donde coincidir, sino que realizan su labor en el ámbito de lo doméstico, provoca el desconocimiento de sus derechos, la dispersión y el aislamiento, haciendo más difícil la intervención en el caso de abusos o vulneración de derechos.

Siendo cierto que frente a la trabajadora doméstica aparece el/la cabeza de familia que, como parte empresarial, tiene derecho a la intimidad personal y familiar, así como a la inviolabilidad de su domicilio (artículos 18.1 y $2 \mathrm{CE})^{3}$. Por tanto, la entrada en el domicilio por la autoridad laboral se contempla, si bien precisa expresamente la necesidad de «salvaguardar los derechos de inviolabilidad de domicilio» y «respeto a la intimidad $»^{4}$. Por tanto, aun solventada la duda sobre si la Inspección de Trabajo y Seguridad Social puede o no ejercitar sus funciones en el marco de esta relación limitada al respeto a los derechos constitucionales reseñados (Cospedal, 1999: 223-228), no marca cómo debe hacerse, ni en qué casos.

Esta colisión de derechos no puede interpretarse en términos absolutos como única razón justificativa de la exclusión del personal del hogar familiar del ámbito de aplicación de la norma preventiva, porque no puede negarse la aplicación del derecho a la seguridad y a la salud laboral de este colectivo, tan sólo

2 Ante los datos de afiliación de la Seguridad Social de diciembre de 2019, observamos que había 396.626 empleadas del hogar. Es decir, el 68,3\% estarían dadas de alta en la Seguridad Social, mientras que el $31,7 \%$ trabajarían en situación irregular.

${ }^{3} \mathrm{La}$ CE (artículo 18.2) declara que el domicilio es inviolable, no pudiendo hacerse en él ninguna entrada o registro sin consentimiento del titular o resolución judicial, salvo en caso de flagrante delito.

4 Véase la Ley 42/1997, de 14 de noviembre, Ordenadora de la Inspección de Trabajo y Seguridad Social. 
porque no sea posible la entrada en el domicilio por parte de la Inspección de Trabajo y Seguridad Social para comprobar si se han adaptado o no las medidas

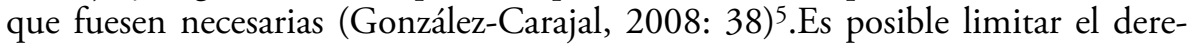
cho a la seguridad y a la salud laboral cuando sea realmente necesario para preservar el derecho que se pretende proteger, pero en este caso no se entiende o no se justifica el negar el citado derecho por razones de protección de la intimidad $y$ de inviolabilidad del domicilio ${ }^{6}$.

En consecuencia, en esta relación laboral, se suelen realizar trabajos sin contratos, con salarios bajos, excesos de horas..., y además estas condiciones se agravan cuando es inmigrante y sobre todo si es irregular y teme exigir sus derechos ya que se encuentran en una posición especialmente sensible (Pérez y López, 2016: 45) ${ }^{7}$, con importantes dificultades para cualquier desarrollo profesional, con derechos muy limitados para negociar el salario o las horas de trabajo y sin ayuda legal para resolver problemas profesionales. En todos estos casos, las exigencias de las personas empleadoras se deslizan por terrenos que bordean la explotación, pero la imposibilidad de inspeccionar el centro de trabajo (Quesada, 2011: 2), por tratarse de un domicilio, hace que no puedan como se señala, contar con el apoyo de la institución administrativa cuya misión es velar por el cumplimiento de la legislación laboral, quedando, debido a este carácter privado, las empleadas domésticas sin forma de probar los hechos en que se basan sus reclamaciones (horarios, salarios, tareas, etc.).

De ahí la importancia que se considera tiene abordar los porqués de la exclusión de este colectivo de personas trabajadoras del ámbito de protección de la LPRL.

\section{Algunas consideraciones generales sobre los aspectos jurídicos de la relación laboral especial de trabajo doméstico que justifican su exclusion de la LPRL}

La regulación laboral de carácter especial del servicio del hogar familiar ${ }^{8}$ mantiene, al menos de manera formal, que esta relación laboral descansa en dos

\footnotetext{
5 Señala que este Derecho Constitucional «no puede producir la conculcación a ultranza del derecho a la seguridad e higiene de quien trabaja y de su derecho a la integridad física». En cambio, algún sector doctrinal defiende la plena corrección de la exclusión al entender que la obligación impuesta al titular choca con el derecho fundamental a la inviolabilidad del mismo.

6 SSTC de 15 de octubre; de 31 de enero; de 19 de julio y de 22 de abril.

7 «El reglamento del empleo del hogar, la ley de dependencia y las políticas de igualdad y extranjería son aspectos clave ya que limitan el acceso a la igualdad de género de las mujeres migrantes, y son una causa de la organización social desigual de los cuidados actualmente».

8 Real Decreto 1620/2011, de 14 de noviembre, por el que se regula la relación laboral de carácter especial del servicio del hogar familiar. (B.O.E. de 17 de noviembre de 2011).
} 
aspectos característicos, como son el ámbito donde se presta la actividad, el hogar familiar y el vínculo personal basado en una especial relación de confianza entre el titular de aquel y las personas empleadas de hogar.

Lo que resulta discutible, en la propia argumentación del Preámbulo del Real Decreto 1620/2011, de 14 de noviembre, por el que se regula la relación laboral de carácter especial del servicio del hogar familiar, es la opción por la autonomía de la voluntad como fuente primordial de la regulación de esta relación, pues no se acaba de entender que el hecho de que el trabajo se preste en el hogar familiar impida a la ley, al propio Real Decreto o incluso a la negociación colectiva una mayor regulación de muchos aspectos de las condiciones de trabajo.

En este sentido, la actual regulación de esta relación laboral, que demuestra deficiencias y cuestiones controvertidas en el régimen jurídico (Salcedo, 2020: 3-9), tenía la intención de acercamiento al régimen legal de la relación laboral común, y por ello, ordenaba expresamente en su Capítulo III la aplicación a los trabajadores de los derechos y deberes laborales establecidos en los artículos 4 y 5 del Estatuto de los Trabajadores (en adelante, ET). En ellos se contiene una que mención expresa al derecho a unas adecuadas condiciones de seguridad y salud en el trabajo ${ }^{9}$ que deberán tener en cuenta las características del trabajo doméstico y cuyo incumplimiento por parte del empleador dará derecho al trabajador a presentar su dimisión. Entiendo, por tanto, que sería conveniente reforzar la protección de esta relación laboral especial y considerar este incumplimiento como una justa causa de extinción del contrato por motivos no imputables al trabajador, según dispone el artículo 50.1.c) del ET. De este modo, tendrían derecho a indemnización como si se tratara de un despido declarado improcedente, aunque en la actualidad no podrían acceder al derecho de la prestación por desempleo. No obstante, no se debe olvidar que la extinción del trabajador ha de ser ponderada con cuidado a la hora de valorar la prueba de que pueda hacer uso el trabajador, con la finalidad de fundamentar la extinción del vínculo contractual. Si no se respeta esto, puede convertirse en una prueba diabólica para el empleado, ya que es el empresario el que tiene los medios de prueba a su alcance y puede utilizarlos de manera intencionada contra el trabajador ${ }^{10}$.

9 No es de aplicación la Ley 31/1995, de 8 de noviembre, de Prevención de Riesgos Laborales, y sus disposiciones de desarrollo en la relación laboral especial del hogar familiar ya que estas normas están pensadas para las empresas y no resultan de aplicación al ámbito del hogar familiar, por estar expresamente excluido en la propia Ley. Solo se exige al empleador a cuidar que el trabajo del empleado de hogar se realice en las condiciones adecuadas de seguridad y salud, debiendo adoptar medidas eficaces para este fin de acuerdo con las características específicas del trabajo a realizar.

10 STSJ del País Vasco de 17 de mayo de 2005: «... la argumentación de la sentencia recurrida debe ser revocada, pues impone a la parte actora una carga diabólica, de difícil superación, atribuyéndole la necesidad de probar que ha existido un despido, y todo ello sobre la base de establecer que ninguna de las partes acredita nada de lo sucedido, y por tanto era la parte actora quien debía probar su pretensión ... Por otro lado, no parece muy acorde con el derecho laboral que si ha existido una vinculación sometida al trabajo por cuenta ajena, sea la trabajadora quien la extinga, para inmediata- 
Y todo ello porque, si bien es cierto que su regulación ha aumentado el ámbito de la protección laboral y de seguridad social, también lo es que una de las principales peticiones de mejora que desde los colectivos de este ámbito se reivindicaba, versaba sobre el todavía no alcanzado reconocimiento del derecho a prestaciones por desempleo.

Esta relación laboral especial presenta una serie de peculiaridades que la dotan de singularidad y la distinguen de la relación laboral común, así como de otras relaciones laborales especiales, y entre ellas que el empresario asume la obligación básica de garantizar la seguridad y salud de los trabajadores en todos los aspectos vinculados al trabajo y el trabajador ha de velar por su propia seguridad y salud conforme a su formación y a las instrucciones emanadas del primero. Esto ha servido a algunos autores para hacer una interpretación particular sobre las motivaciones que han podido llevar al legislador a la inclusión o exclusión de este colectivo en el ámbito de aplicación de la Ley de Prevención de Riesgos Laborales (en adelante, LPRL). Así pues, unos aluden a exclusión «aparente o parcial» (González-Carvajal, 2000:58), mientras que otros insisten en la consideración de exclusión "absoluta» (VV.AA., 1997: 41) e, incluso, otros refieren a una "situación paradójica y contradictoria» en la medida en que señala que «de forma simultánea se niega la aplicación de la normativa sobre prevención de riesgos laborales y se afirma el derecho de los trabajadores domésticos a desarrollar su prestación en unas condiciones óptimas de seguridad y salud en el trabajo» (VV.AA., 2001: 68-69).

Según el artículo $39^{\circ} .2$ la LPRL no será de aplicación a las actividades cuyas particularidades lo impidan en el ámbito de las funciones públicas de policía, seguridad y resguardo aduanero; así como en los servicios operativos de protección civil y peritaje forense en los casos de grave riesgo, catástrofe y calamidad pública. Las actividades no se excluyen por el trabajo a que pertenecen (policía, seguridad, protección civil), sino en los aspectos incompatibles con las medidas establecidas en la norma. No obstante, se añade que la LPRL inspirará la normativa específica que se dicte para regular la protección de la seguridad y salud de los trabajadores que prestan sus servicios en las indicadas actividades. De la misma manera, el artículo 3. ${ }^{\circ} .3$ prevé la aplicación de la LPRL en los centros militares y penitenciarios con las necesarias particularidades.

En éste sentido, recordemos que la LPRL derogó los títulos I y III de la Ordenanza General de Seguridad e Higiene en el Trabajo aprobada por Orden de

mente presentar una papeleta de demanda de conciliación, pues ante la situación de falta de trabajo que acontece en nuestro país, lo más lógico parece el intento de conservar la relación laboral, y más cuando la misma queda en un arcano que solamente es imputable al empresario, que no presenta ningún tipo de documento del cual poder deducir que la relación se mantenía dentro de unos parámetros ordinarios de trabajo, y cuya protección establece el RD 1424/1985, de uno de agosto, en relación al artículo 2, n. ${ }^{\circ} 1$ ap. B) ET...». 
9 de marzo de 1971, y con ello su artículo $1 .^{\circ}$, que extendía el campo de aplicación de esta Ordenanza a todas las personas comprendidas en el ámbito del Sistema de la Seguridad Social, al establecer: «a las disposiciones de esta Ordenanza se ajustará la protección obligatoria mínima de las personas comprendidas en el ámbito del Sistema de la Seguridad Social, a fin de prevenir accidentes y enfermedades profesionales y de lograr las mejores condiciones de higiene y bienestar en los centros y puestos de trabajo en que dichas personas desarrollen sus actividades».

Como podemos comprobar, la Ordenanza incluía la protección de los trabajadores domésticos, ya que según la Disposición Adicional del Real Decreto 1424/1985, la normativa laboral común se aplica en lo que resulte compatible con las peculiaridades derivadas del carácter especial de la relación ${ }^{11}$.En definitiva, al excluir el trabajo doméstico, la LPRL supuso un retroceso en la regulación de la Seguridad Laboral en esta relación laboral especial (García, 1995: 178) ${ }^{12}$.

La exclusión en la Ley de Prevención de los trabajadores domésticos se fundamenta, tanto por la especial interrelación que en el trabajo de servicio del hogar familiar existe entre las condiciones laborales del trabajador y las del empleador, como por las peculiaridades del lugar donde se presta el trabajo que complican la aplicación de determinadas previsiones normativas generales en materia de seguridad y salud en el trabajo (Pérez, 1991: 50) ${ }^{13}$.No obstante, respecto del concepto de hogar familiar cabe señalar que se trata de un término muy amplio debido a la dificultad de dar un concepto unitario de familia como consecuencia de la aparición de diversas formas de convivencia (Ramírez, 1986: 48) ${ }^{14}$.

Pero entiendo que la justificación de la exclusión sobre la base del lugar específico carece de fundamento ya que existen otras figuras tales como el trabajo de ayuda a domicilio que no han sido excluidos. Sin embargo, la realidad demuestra que no se hace ningún tipo de evaluación de riesgos laborales en los centros de trabajo donde las personas trabajadoras de ayuda a domicilio realizan

11 También era aplicable, hasta que dejó de estar vigente con la derogación operada por Ley 11/1994 de 19 de mayo, el artículo 48 de la Ley de Contrato de Trabajo que establecía que «si el trabajador fuere admitido a vivir en la casa del patrono o a cargo de la empresa, o a ser sustentado por ella, las condiciones del local, dormitorios y comidas habrán de ser los adecuados a su situación, estado, exigencias de la moralidad e higiene...".

${ }^{12}$ GARCÍA VALVERDE afirma que no existe norma legal a la que acogerse para garantizar las debidas condiciones de seguridad e higiene que han de regir.

${ }^{13}$ Así lo reconoce PEREZ DE LOS COBOS ORIHUEL al referirse al fundamento de exclusión de este colectivo en la norma comunitaria.

${ }^{14} \mathrm{La}$ «titularidad del hogar familiar» que convierte a uno de los convivientes en empleador no es sino una ficción que eleva a la categoría de empleador a una de las personas que habitan en el inmueble con el objeto de facilitar trámites y gestiones. Así lo demuestra ese artículo 1.3 RD 1620/2011 cuando atribuye esa titularidad del hogar familiar a un representante de esas personas que conviven juntas y admite que tal posición se asuma sucesivamente por todas ellas. 
su actividad laboral. Siendo también el principal argumento el artículo 18.2 CE, pero en este supuesto, contradice los principios básicos de la LPRL, en cuya la lista exhaustiva y cerrada en la que se excluyen las relaciones laborales sobre las cuales no impera su aplicación, como el trabajo doméstico, no se incluye las trabajadoras/es de ayuda a domicilio.

Además, el domicilio, como lugar de prestación a la persona beneficiaria de la de ayuda a domicilio, es donde se va a ejecutar dicha prestación, por lo que la habitabilidad y condiciones de movilidad dentro del mismo es una condición sine qua non para poder conceder la prestación, por lo que el análisis sobre las características del mismo debería quedar patente en el informe social que la Administración local lleva a cabo, previamente a la concesión de dicho servicio.

Del análisis anterior no caben dudas sobre la aplicación de la LPRL a la actividad concreta de la ayuda a domicilio: así, resulta que en el domicilio del beneficiario, lugar de prestación del servicio público y lugar de trabajo de esta ayuda, se despliega todo el impacto protector de la Ley de prevención de riesgos laborales, no encontrándose esta actividad laboral incluida en el catálogo de exenciones como se hizo con las personas trabajadoras de hogar, y así subsiguientemente lo hubieran contemplado los convenios colectivos y los contratos administrativos. No parece, por tanto, que alegar como excusa el lugar de prestación de servicios sea suficiente para vincular esta distinción de protección que resulta carente de elementos objetivos que la fundamente para el trabajo doméstico, y que no lo es para la ayuda a domicilio, y que, al mismo tiempo, contraría el artículo $41 \mathrm{CE}$ y el artículo 14 del Convenio n. ${ }^{\circ} 189$ de la OIT, de 16 de junio de $2011^{15}$, al que me referiré en apartados posteriores.

En este sentido, el Tribunal Supremo, en su sentencia de 20 de febrero de 1989 establecía que «la esfera privada... incluye aquel sector de circunstancias que, sin ser secretas ni de carácter íntimo, merecen, sin embargo, el respeto de todos, por ser necesarias para garantizar el normal desenvolvimiento y la tranquilidad de los titulares particulares...» De ello se deduce el distinto tratamiento que da el Alto Tribunal a la vida privada y a la intimidad (Cabezuelo, 1998: 18).

En este sentido, basta recordar las afirmaciones del TC relativas a que «el derecho a la intimidad limita la intervención de otras personas y de los pode-

15 Artículo 14 Convenio n. ${ }^{\circ} 189$ de la OIT: «1. Todo Miembro, teniendo debidamente en cuenta las características específicas del trabajo doméstico y actuando en conformidad con la legislación nacional, deberá adoptar medidas apropiadas a fin de asegurar que los trabajadores domésticos disfruten de condiciones no menos favorables que las condiciones aplicables a los trabajadores en general con respecto a la protección de la seguridad social, inclusive en lo relativo a la maternidad.2. Las medidas a que se hace referencia en el párrafo anterior podrán aplicarse progresivamente, en consulta con las organizaciones más representativas de los empleadores y de los trabajadores, así como con organizaciones representativas de los trabajadores domésticos y con organizaciones representativas de los empleadores de los trabajadores domésticos, cuando tales organizaciones existan». 
res públicos en la vida privada ${ }^{16}$. De esta forma el derecho a un núcleo inaccesible de intimidad se reconoce incluso a las personas más expuestas al público ${ }^{17}$. La intimidad, de acuerdo con el propio precepto constitucional, se reconoce no sólo al individuo aisladamente considerado, sino también al núcleo familiar ${ }^{18}$.

Existe de este modo, una estrecha relación entre la inviolabilidad del domicilio (Alonso, 1993: 84) y la intimidad personal y familiar garantizada en el artículo 18.1 CE ${ }^{19}$. Esta relación fue ya formulada por la STC 22/1984, de 17 de febrero «El domicilio inviolable es un espacio en el cual el individuo vive sin estar sujeto necesariamente a los usos y convenciones sociales y ejerce su libertad más íntima. Por ello a través de este derecho no sólo es objeto de protección el espacio físico en sí mismo considerado, sino lo que en él hay de emanación de la persona y de esfera privada de ella.» Hay, pues, un nexo de unión indisoluble entre los apartados 1 y 2 del artículo 18 CE.

Ahora bien, a efectos de la prevención que es el tema que nos ocupa, como he señalado, el lugar en que se desarrolla el trabajo no parece justificar su exclusión (VV.AA., 1987: 48; Schneider,1990: 374 y 375) ${ }^{20}$, parece más acertado pensar, que la ausencia de regulación se debe a las dificultades existentes en cuanto a la aplicación de la Ley en esta relación laboral. Recordemos que la propia Exposición de Motivos del Real Decreto 1424/1985 establecía que la especialidad se encontraba en el propio ámbito donde se desarrolla la prestación de servicios, en la mutua confianza y flexibilidad que ambas partes se conceden recíprocamente.

A todo ello debe añadirse que cuanto menos resulta desconcertante la exclusión, si se compara con otras figuras incluidas en el ámbito de la legislación preventiva como puede ser el trabajo a domicilio, dado que parte de los problemas que relacionan serian comunes a ambas relaciones laborales (García, 1995: 170-171).

16 STC de 25 de abril de 1994.

17 STC de 15 de julio de 1999.

18 SSTC de 17 de octubre de 1991 y de 2 de diciembre 1988.

19 SSTC 160/1991 y 69/1999, de 26 de abril.

20 Justificar esta exclusión sobre la base del lugar carece de fundamento, ya que existen otras figuras, tales como el trabajo a domicilio, que no han sido excluidas. Además, el concepto de hogar familiar es muy amplio debido a la dificultad de dar una definición unitaria de familia como consecuencia de la aparición de nuevas y diversas formas de convivencia. Esta interpretación puede verse también en La relación laboral especial de servicio del hogar familiar, Es evidente que la característica que permite identificar este tipo de relación de carácter especial es el concepto "hogar familiar», desde un doble punto de vista: El empresario es el «titular» del hogar familiar y los servicios se prestan «en el ámbito del hogar familiar» Ahora bien, este concepto ha quedado superado, tanto desde el punto de vista físico, del espacio, como de los moradores del mismo, o sea, los familiares, de manera que son varias las sentencias que admiten la prestación de este tipo de servicios fuera del hogar familiar (STSJ Castilla y León/Burgos 30 de abril de 2002).; incluso cuando la persona fue contratada para trabajar en la atención y cuidado de los hijos menores del titular del hogar familiar, con horario permanente, trasladándoles al colegio, dándoles de comer y cuidándoles, en el domicilio de domicilio de la empleada doméstica mientras sus padres trabajaban (STSJ Cantabria 11 de mayo de 2000). 
Por otro lado, se debe indicar que la exclusión de los trabajadores domésticos de la LPRL es conforme con lo dispuesto en el artículo 3 de la Directiva 89/391/CEE de 12 de junio, relativa a la aplicación de medidas para promover la mejora de la seguridad y de la salud de los trabajadores en el trabajo, conocida como Directiva marco ${ }^{21}$. A excepción del trabajo doméstico, es aplicable a todos los sectores de actividades públicas y privadas, con la excepción de «las particularidades inherentes a determinadas actividades inherentes de la función pública, por ejemplo, en las fuerzas armadas o de la policía, o a determinadas actividades específicas en los servicios de protección civil» (Pérez, 1991: 50).

Una lectura rápida de ese artículo podría hacernos pensar que no son las personas trabajadoras de dichos sectores sino algunos de sus cometidos los que se exceptúan de la protección de la norma, por lo que ni la Directiva, ni la LPRL, en principio justifican la exclusión (Ayala, 2007: 6), pero esa conclusión no sería del todo correcta, ya que lo que excluye son las actividades que realizan en situaciones excepcionales para garantizar la seguridad y la protección de la vida e integridad de las personas, objetivo que podría no conseguirse si en dichas intervenciones se tuvieran que aplicar la totalidad de las disposiciones recogidas en la normativa sobre prevención de riesgos laborales.

Al mismo tiempo, según las Directivas comunitarias 93/104 de 23 de noviembre de 1993 y 2003/88 de 4 de noviembre de 2003 sobre ordenación del tiempo de trabajo, la fijación de la duración de la jornada y los descansos es un elemento de seguridad y salud laboral ${ }^{22}$. Pero las Directivas citadas se remiten a

${ }^{21}$ STSJ de Castilla y León de 9 de enero de 2017, en relación a un accidente laboral de empleada de hogar, pero en este caso analizando la posible normativa aplicable sobre escaleras de mano, el TSJ recuerda que en el ámbito de la Unión Europea los trabajadores al servicio del hogar familiar están excluidos del ámbito de aplicación de las normas de seguridad y salud laboral con carácter general, salvo cuando en alguna concreta directiva se establezca lo contrario, lo que no es el caso de la Directiva 89/654. La escalera con la que la trabajadora sufrió el accidente era la habitual de uso cotidiano, con travesaños horizontales, tenía dispositivos antideslizantes, y era de tijera, con enclavamiento de la posición, lo que avala el cumplimiento del deber general de cuidado que recaía sobre el titular de la vivienda y lleva a confirmar la desestimación de la acción. Para determinar si el equipo de trabajo era adecuado no son necesariamente aplicables las normas de seguridad y salud laboral de forma directa e íntegra, pero incluso si hubiéramos de aplicar las mismas como a cualquier otro trabajador por cuenta ajena en una relación laboral ordinaria, no aparece probado que se haya producido en este caso una vulneración de la normativa sobre escaleras de mano.

22 STSJ Andalucía de 13 de diciembre de 2017. Revocando Sentencia del Juzgado de lo Social número Dos de Málaga, por la que se había considerado que aun cuando la empleada interna se encontrara al tiempo del ictus en su lugar de trabajo — que coincide con el de residencia - no estaba en tiempo de trabajo ni desplegando actividad laboral efectiva alguna, no existía contingencia profesional al considerar el ictus cerebral padecido mientras dormía como una etiología común sin conexión directa con la actividad laboral desplegada, el TSJ de Andalucía, ha entendido que el evento lesivo padecido por la demandante se produjo en el lugar y en tiempo de trabajo, o como mínimo "... en unas condiciones que guardan una intima conexión con el trabajo...". Para el TSJ, la presunción de laboralidad establecida en el artículo 115.3 de la Ley General de la Seguridad Social, es suficiente para declarar que la contingencia del proceso de incapacidad temporal seguido por la trabajadora es 
la Directiva marco para la definición de trabajador protegido, y en consecuencia excluye de nuevo al empleo de hogar (López y Toscani, 2006: 47) ${ }^{23}$.

Probablemente la solución más viable hubiese sido, como ya se ha indicado, que el legislador hubiera optado por aplicar la normativa contenida en la LPRL (González y Aparicio, 1996: 64), salvo en determinadas cuestiones en las que se recurriría a una normativa reglamentaria específica para solventar aquellos aspectos que no fueran compatibles con las peculiaridades de la relación laboral especial. A este respecto se apuntan otras posibles soluciones tales como las que arbitra cierto sector doctrinal referidas a la posibilidad de mantener este tipo de relación al margen del ámbito de aplicación de la LPRL y haber previsto una futura regulación reglamentaria (García, 1995: 172-173).

En todo caso, la exclusión de la LPRL viene referida a la relación de las empleadas de hogar y no incluiría a quienes prestan su trabajo por cuenta de empresas de servicios o en el Servicio de Ayuda a Domicilio (en adelante, SAD) de la Ley 39/2006, de 14 de diciembre, de Promoción de la Autonomía Personal y Atención a las personas en situación de dependencia. Por lo que parece injustificable que si en el SAD, el cuidado personal va unido a las tareas domésticas propias de una empleada de hogar con lo que, especialmente en el caso de quienes atienden personas en situación de dependencia, los riesgos son los mismos: caídas, golpes con objetos, trastornos musculoesqueléticos derivados de movimientos repetitivos o posturas de trabajo inadecuadas (Rodríguez, 1998: $2633)^{24}$, cortes, atrapamientos, quemaduras, dermatosis, alergias respiratorias ${ }^{25}$ e incluso riesgos particulares del hogar en que se desarrolla el trabajo (Ayala, 2007: 15).

derivada de accidente de trabajo. En esta ocasión, las características especiales que median en la profesión de la demandante, empleada de hogar y cuidadora de dos personas de avanzada edad con las que convive, difícilmente permite diferenciar los tiempos de trabajo de los de descanso, por lo que recae sobre los empleadores, que habían desentendido por completo el cumplimiento de sus obligaciones de alta y cotización, la responsabilidad en cuanto al abono de las prestaciones de incapacidad temporal correspondientes.

23 Entienden que las Directivas sí son de aplicación.

${ }^{24}$ En la prevención de los riesgos en estos ámbitos son de aplicación medidas que se han establecido para sectores que tienen la cobertura de la LPRL y se dedican a las mismas tareas en el marco de una relación ordinaria, principalmente el RD 487/1997, de 14 de abril, sobre prevención en las actividades que requieren manipulación manual de cargas que entrañe riesgos, en particular dorsolumbares, para los trabajadores, o el RD 486/1997, de 14 de abril, sobre seguridad y salud en los lugares de trabajo, y las correspondientes guías técnicas del Instituto Nacional de Seguridad e Higiene en el Trabajo. RODRÍGUEZ INIESTA, G., "reconoce que "las tareas de un empleado de hogar se caracterizan porque requieren cierta agilidad y se desarrollan normalmente en continuas situaciones de bipedestación y deambulación prologadas».

${ }^{25}$ La Guía de buenas prácticas para la Prevención de Riesgos en la Ayuda a Domicilio, de la Fundación para la prevención de riesgos laborales, de la UGT, recoge de manera sistemática los que se pueden producir. Las Mutuas tienen editados manuales y guías de prevención para los trabajos de limpieza y manejo de cargas, así como los riesgos sicosociales, aplicables al empleo de hogar. 
En definitiva, una vez incluido en la LPRL el trabajo a domicilio, fórmula de prestación de servicios por cuenta ajena en la que la norma también es difícil aplicar (García y García, 2005: 16; Moreno y Marín, 2004: 8), la exclusión del trabajo doméstico, entiendo no está en absoluto justificada.

\section{Supuestos de responsabilidad del empleador en los riesgos laborales de esta relación laboral especial}

Como ya hemos podido advertir, el artículo 3.4 LPRL dispone que el titular del hogar familiar está obligado a cuidar de que el trabajo de sus empleados se realice en las debidas condiciones de seguridad e higiene, pero no añade contenido a la obligación genérica sobre seguridad y salud laboral recogida en los arts. 4. 2, d) y 19.1 ET.

Así mismo, el Real Decreto 1620/2011, en su artículo13 establece que «el titular del hogar familiar está obligado a cuidar de que el trabajo de sus empleados se realice en las debidas condiciones de seguridad de higiene. La deficiencia grave de estas obligaciones es justa causa de dimisión del empleado".

Como observamos, es una mera declaración sobre el deber del empleador de ofrecer las debidas condiciones de seguridad laboral, pero además ni define cuáles sean aquellas (Igartua, 2008: 68), ni tiene fuerza coercitiva ante el vacío tipificador frente a las conductas reprochables, cuya sanción administrativa no encuentra cobertura legal ni dentro ni fuera de la LPRL. Entonces, no parece sencillo en qué caso se podría plantear la existencia de responsabilidad empresarial por un accidente doméstico que, sin embargo, para la persona trabajadora es de trabajo. En el terreno laboral, la diligencia exigida al empresario consiste en aplicar, en primer lugar, las medidas previstas en la legislación específica; en segundo lugar, las medidas que se deducen del estado de la técnica en cada momento, y de la experiencia, esto es la previsibilidad del riesgo y poder evitarlo.

En tanto que el empresario organiza y dirige los servicios en un ámbito determinado, por tal condición debe conocer y evitar los riesgos generados (De Dios, 2015: 7), yendo más allá de la media requerida en el hacer de cualquier persona. Pero nos encontramos que en el supuesto de seguridad del empleado doméstico no se muestra tan rigurosa, prueba de ello es que según el artículo 7.2 del Real Decreto 1620/2011, el incumplimiento de las obligaciones de seguridad tiene que ser grave para dar lugar a la dimisión de la trabajadora doméstica. Lo que resulta criticable, pues en estos casos lo razonable es que la trabajadora, como ya propuse, pueda solicitar la resolución del contrato de trabajo con la indemnización correspondiente al despido improcedente (artículo 50.1.c) del ET), ya que existe una auténtica dificultad para acreditar el incumplimiento grave de la persona empleadora por la limitación de la facultad de entrada al centro de trabajo 
y las dificultades de fiscalización del mismo por parte de la Inspección de Trabajo cuyo resultado puede entonces derivar en una total inaplicación del derecho. En otras palabras, el trabajador no puede decidir de manera unilateral que es un incumplimiento grave y abandonar su puesto de trabajo, ya que ese comportamiento se considerará como baja voluntaria sin derecho a indemnización.

En todo caso, reitero que en materia de prevención de riesgos el problema fundamental es la dificultad que plantea el control de la obligación de cuidado impuesta al empleador, dado que la inviolabilidad del domicilio limita en gran medida la actuación inspectora ${ }^{26}$. Es un problema que afecta, en general, a todo el régimen de garantías aplicable a esta relación laboral especial (Desdentado, 2016: 129-148).

En cualquier otra actividad, los estándares de seguridad e higiene se refieren a equipos de trabajo, condiciones de los lugares de trabajo, operaciones, procesos y actividades que generan riesgo para la salud física o psicológica. La actividad doméstica, cuando ha sido investigada bajo el prisma de la seguridad y salud laboral, ha resultado ser «un trabajo penoso o duro, que conlleva posturas forzadas y grandes esfuerzos constantes $»^{27}$. Por lo que «la vigilancia de la salud tiene, además, unas utilidades específicas para el trabajador individual por cuanto permiten detectar precozmente alteraciones de la salud relacionadas con el trabajo y gestionar una adecuada atención actuando tanto sobre la persona como sobre los posibles riesgos laborales» (López, 2014: 473-480).

En el supuesto de elementos que tengan claramente especificadas sus instrucciones de uso, se podrán aplicar, si no los preceptos de la LPRL sobre deber de información y culpa in vigilando, sí el juicio de culpabilidad o negligencia en caso de órdenes de trabajo que contravengan las disposiciones sobre seguridad de un producto en concreto, o supongan riesgos evidentes no asumibles por la trabajadora.

Es cuanto menos complicado dictaminar si se incurre en acción u omisión antijurídica cuando la obligación de seguridad tiene un perfil tan indeterminado como la frase «debidas condiciones» de seguridad e higiene. En el orden social, se ha considerado no responsable al empleador que se limitó a dar la orden de trabajo sin intervenir en el cómo de su realización ${ }^{28}$; en el mismo orden en cambio,

26 La Inspección de Trabajo y de la Seguridad Social necesitará la autorización del titular del domicilio para poder entrar en el hogar donde se desarrolla la prestación; en su defecto, deberá solicitar la autorización judicial, con la consiguiente demora en la actividad inspectora y el riesgo de ocultación de los actos constitutivos de infracción.

27 Según el estudio realizado en 1998 por SMA, Management, S.L., por encargo de EmakundeInstituto Vasco de la Mujer, Valoración de la carga física en las Empleadas de Hogar de Bizkaia, publicado en www.ath-ele.com.

28 La STSJ Islas Baleares, de 3-11-2005, «la existencia de incumplimiento no deriva de la circunstancia de que las hojas de la ventada solo se abrieran $90 .^{\circ}$, de que se usara una escalera para lim- 
se ha atribuido culpa contractual a quien dio la orden sin advertencias de seguridad y presenció la operación peligrosa que dio lugar al accidente ${ }^{29}$. Del mismo modo que la ausencia de disposición concreta, que obligase al empleador a proporcionar calzado especial o hacer un sendero que evitase a la trabajadora cruzar el césped cargada con la ropa que debía colgar en el tendedero, exime de responsabilidad al empleador en la caída que sufrió ${ }^{30}$.

De manera que, si pese a que la Ley 27/2011 dejó pendiente la equiparación del sistema de cotización y la cobertura de los vacíos en el cálculo de las pensiones de las empleadas de hogar al régimen general de la Seguridad Social para 2019 y, luego, la enmienda 6777 de la Ley de Presupuestos Generales de 2018 la retrasó a 2024, n puede negarse que la voluntad del legislador siga siendo que esta relación laboral especial tenga las mismas coberturas que el Régimen General de la Seguridad Social. Tal y como advertimos al hacer referencia a la Ley 39/2010 de 22 diciembre, de Presupuestos Generales del Estado, se incorpora vía la Disposición Adicional Quincuagésima Tercera a la LGSS -rubricada «Extensión de la acción protectora por contingencias profesionales a los trabajadores incluidos en el Régimen Especial de la Seguridad Social de los Empleados de Hogar» que en su apartado 1 prevé "que con efectos 1 de Enero de 2011, se amplía la acción protectora del Régimen Especial de la Seguridad Social de los Empleados de Hogar, incorporando la correspondiente a las contingencias de accidentes de trabajo y enfermedades profesionales».

Por analizarlo desde otro punto de vista, el artículo 1.104 del Código Civil (en adelante, CC) define la culpa o negligencia como la omisión de aquella diligencia que exija la naturaleza de la obligación y corresponda a las circunstancias de las personas, del tiempo y del lugar. Y cuando la obligación no exprese la diligencia que ha de prestarse en su cumplimiento, se exigirá la que correspondería a un buen padre de familia. Pero el problema de la aplicación de estas disposiciones está en el concepto de previsibilidad, ya que según el artículo 1105 CC, nadie responderá de los sucesos que no hubieran podido preverse, por lo que solo la culpa o falta de diligencia debida puede reprocharse en relación con sucesos previsibles ${ }^{31}$.

piar los cristales superiores, o de que se colocara esta paralela o perpendicular a la ventana. No se dice cuál es la medida de protección o seguridad que se omitió y no se ve cual pudiera ser salvo el haber cerrado la persiana durante la operación de limpieza de los cristales superiores o no haberla abierto, pero de la circunstancia de que la trabajadora no adoptara tal precaución, seguramente por entenderla innecesaria, no puede derivarse la imputación de responsabilidad para el cabeza de familia respecto de quien no se ha acreditado ningún actuar culpable».

29 SAP Asturias, 27 de enero de 2005.

30 STSJ País Vasco de 4 de noviembre de 2003.

31 En palabras del Tribunal Supremo, "la exigencia de la previsibilidad hay que considerarla en la actividad normal del hombre medio con relación a las circunstancias, desde el momento en que no puede estimarse previsible lo que no se manifiesta con constancia de poderlo ser (...)", STS de 1 de octubre de 1998. 
Con la evaluación de riesgos que dispone la LPRL, solo quedan fuera del campo de imputabilidad los acontecimientos verdaderamente fortuitos: la previsión forma parte de la deuda de seguridad. Por el contrario, por muy injusto que sea el daño, si no existe el deber de evaluar el riesgo en la actividad laboral doméstica, el campo de aplicación del deber de diligencia queda reducido a los peligros que puedan anticiparse con la diligencia exigida por el artículo 1104 CC.

Pero como vemos, a modo de conclusión, la LPRL no hace referencia a ninguna de las singularidades optando por una exclusión absoluta de esta relación laboral especial, lo que sí manifiesta es la existencia de una colisión entre los derechos que operan en el ámbito del hogar familiar y el derecho a la seguridad y salud laboral del trabajador que presta servicios en ese espacio.

No obstante, debemos advertir que la exclusión no significa que a estos trabajadores se les niegue su derecho a la seguridad y salud laboral ya que como hemos indicado a este respecto, se hace referencia en el artículo 3.4 LPRL a la obligación legal del titular del hogar familiar de cuidar que el trabajo de sus empleados se realice «en las debidas condiciones de seguridad e higiene» (Fernández, 1996: 35; Guadalupe, 1989: 161-162.) ${ }^{32}$. En consecuencia, la norma los excluye, pero al mismo tiempo les ofrece una protección en materia de prevención de riesgos laborales, aunque finalmente, señala cuál es la naturaleza jurídica de esta relación laboral especial en conexión con la LPRL.

En lo que concierne a la responsabilidad empresarial, no puedo dejar de plantearme si también ha sido voluntad del legislador, extender al cabeza de familia el pago de las prestaciones por incumplimiento de las obligaciones en materia de Seguridad Social, previsto en el artículo 126 de la LGSS.

Del tenor literal de la misma y teniendo en cuenta que en el Sistema Especial de Empleados de Hogar se genera derecho a las prestaciones por contingencias profesionales al igual que en el Régimen General, se podría entender que a este Sistema Especial también le es de aplicación el régimen de responsabilidades previsto en este artículo de la LGSS.

Sin embargo, me parece apropiado distinguir dos situaciones diferentes ante este planteamiento. La primera es que la prestación económica de empleado de hogar derivada de contingencias comunes, el empleado de hogar genera derecho a la prestación económica, siendo responsable a priori, el cabeza de familia de la falta de afiliación, alta, baja, cotizaciones en Seguridad Social, pero al entrar en juego la segunda, es decir, cuando el empleado de hogar genere derecho a una

32 Se excluye la relación laboral especial de servicio del hogar familiar, en términos que no dejan de ser contradictorios. El principio general es la exclusión del campo de aplicación de la Ley, para añadir seguidamente que: «el titular del hogar familiar está obligado a cuidar de que el trabajo de sus empleados se realice en las debidas condiciones de seguridad e higiene (...)». 
prestación económica derivada de contingencias profesionales y el cabeza de familia, haya incumplido las obligaciones de afiliación, alta o cotización, solo y exclusivamente el cabeza de familia responde del pago de las cotizaciones y de las sanciones que se deriven según lo preceptuado en la Ley de Infracciones y Sanciones en el Orden Social.

A tenor literal de las normas, la Disposición Adicional Trigésima Novena, de la Ley 27/2011, de 1 de agosto en su apartado 3 letra c establece que "con respecto a las contingencias profesionales del Sistema especial para Empleados de Hogar, no será de aplicación el régimen de responsabilidades en orden a las prestaciones regulado en el artículo 126 del Texto Refundido de la Ley General de la Seguridad Social, según lo dispuesto en el apartado 3 de la disposición adicional quincuagésima tercera de esta misma Ley». Por tanto, para el Sistema Especial de Empleados de Hogar, integrado en el Régimen General, desaparece el régimen de responsabilidad empresarial en materia de prestaciones cuando la contingencia derive de contingencias profesionales.

En síntesis, la voluntad del legislador parece clara, su intención fue realizar una integración parcial del antiguo Régimen Especial de Empleados de Hogar dentro del Régimen General, garantizándoles las coberturas de prestaciones derivadas de contingencias profesionales, y excluyendo el régimen de responsabilidades del cabeza de familia ante el incumplimiento de las obligaciones en materia de Seguridad Social. Desde mi punto de vista, no debemos obviar que ante supuestos de hechos iguales, las consecuencias jurídicas prevista en las normas son distintas.

\section{El imposible control del trabajo doméstico: el papel fundamental de la inspección de trabajo}

Como ya se ha podido reparar en párrafos anteriores, la Ley de Prevención no hace referencia a ninguna de las singularidades optando por una exclusión absoluta de esta relación laboral especial, lo que sí manifiesta es la existencia de una colisión entre los derechos que operan en el ámbito del hogar familiar y el derecho a la seguridad y salud laboral del trabajador que presta servicios en ese espacio.

Desde una visión crítica con la exclusión, se ha indicado que tiene que ver con la colisión de las funciones inspectoras con el derecho a la intimidad, contemplándose la posibilidad de haber regulado el control de las condiciones de seguridad de los instrumentos de trabajo, pero no más allá (VV.AA., 2008: 68). Sin embargo, el derecho a la intimidad, como el resto de los derechos fundamentales, comprendemos que tiene límites, algunos establecidos por la propia $\mathrm{CE}$ y otros derivados de la necesidad de proteger otros derechos u otros bienes constitucionalmente protegidos. 
Por ésta razón existen multitud de dificultades para las autoridades laborales (la Inspección de Trabajo y Seguridad Social), para velar por el cumplimiento de la normativa vigente, no sólo en materia de seguridad y salud en el trabajo sino en todo lo que afecta a las condiciones de trabajo, ya que el control debe efectuarse, con respeto del derecho a la inviolabilidad del domicilio ${ }^{33}$, sometiendo la actuación de la Inspección de Trabajo y Seguridad Social a las facultades y límites contemplados en el artículo 13.1 de la Ley 23/2015, de 21 de julio, Ordenadora del Sistema de Inspección de Trabajo y Seguridad Social se dispone que «Si el centro sometido a inspección coincidiese con el domicilio de la persona física afectada, deberán obtener su expreso consentimiento o, en su defecto, la oportuna autorización judicial». Por lo que los únicos títulos habilitantes para la entrada en el domicilio son el consentimiento del titular o la autorización judicial ${ }^{34}$.

Como vemos, y debido al marco privado en el que se desarrolla la prestación de servicios, en la mayoría de los casos, las empleadas de hogar se enfrentan a la sistemática negativa de Inspectores y Subinspectores Laborales a intervenir en un terreno que se considera privado. Desde la tutela de la inviolabilidad domiciliaria o desde la intimidad personal, se impide la aplicación de las normas laborales y de los derechos constitucionales que van a resultar incompatibles con la aplicación de determinadas medidas preventivas (Conde-Pumpido, 2003: 281-331), especialmente como indicamos, la dificultad de compatibilizar el control de la autoridad laboral del cumplimiento de las normas de prevención, con el respeto a la intimidad y la inviolabilidad del domicilio (De la Villa, 1985: 221; López, 2000: 170).

Este RD 1620/2011, también recoge otras disposiciones, aplicables a esta relación laboral de carácter especial, referentes al control de cumplimiento de la legislación laboral a cargo de la Inspección de Trabajo y Seguridad Social (Capítulo IV) y atribuye el conocimiento de los conflictos a la jurisdicción social, reproduciendo los términos del correlativo de la norma anterior.

En la normativa común, podemos observar en artículo 13 de la Ley 23/2015, de 21 de julio citada, podrá «entrar libremente en cualquier momento y sin previo aviso en todo centro de trabajo. Establecimiento o lugar sujeto a inspección y a permanecer en el mismo», pero aclara que si el centro sometido a inspección coincidiese con el domicilio de la persona física afectada deberán ob-

33 El concepto domicilio, aunque esencialmente es de naturaleza civil y se encuentra regulado en los artículos 40 y siguientes del Código Civil, también presenta diversas regulaciones en otras normas del Ordenamiento Jurídico, entre las que cabe destacar las leyes procesales, las mercantiles o las tributarias. En todo caso, hay que incluir cualquier tipo de espacio donde se desarrollen actividades de tipo doméstico, ya sean viviendas o habitaciones, por ejemplo, si se prestan los servicios en una habitación de hotel donde reside, habitual o temporalmente, el empresario, fijas o móviles, como pueden ser embarcaciones. Sobre los domicilios temporales véase, entre otras, SSTCT de 19 de octubre de 1983, de 26 de diciembre de 1983, de 9 de marzo de 1984 y de 10 de noviembre de 1984 .

34 STSJ de Madrid, de 24 de noviembre de 2008. 
tener su expreso consentimiento ${ }^{35}$ o, en su defecto, la oportuna autorización judicial $^{36}$. Por lo tanto, debemos considerar que en el caso de que la Inspección de Trabajo quiera verificar el cumplimiento de la nueva normativa de los empleados del hogar con una inspección en un domicilio particular, el domicilio sería centro de trabajo, pero únicamente durante las horas que realiza el trabajo el empleado del hogar, pero si no hay consentimiento, y salvo que exista orden judicial, la Inspección, no podrá entrar en el citado domicilio ${ }^{37}$.

El consentimiento del titular, aunque no es necesario que sea formal, debe ser inequívoco, a cuyos efectos la inspección debe informarle adecuadamente sobre el derecho a negar la entrada en su domicilio, sin que sea admisible ningún tipo de coacción o intimidación. En su caso, el titular puede aceptar la entrada sólo en una zona en concreto de su domicilio, negando al acceso, al resto, pudiendo, en este caso, la inspección, de estar disconforme con ello, proceder a solicitar la autorización judicial.

También puede el titular, en cualquier momento, revocar el consentimiento prestado, debiendo los actuarios, en ese caso, abandonar inmediatamente el domicilio. En el caso de pluralidad de moradores el consentimiento lo puede otorgar cualquiera de ellos.

No olvidemos que la autorización judicial o requiere la previa negativa del titular (es decir, se requiere en defecto de consentimiento, pero no, indefectiblemente, para suplir la falta de consentimiento) ${ }^{38}$; en cualquier caso, al tener

35 STC de 17 de enero, respecto de la inviolabilidad del domicilio.

36 Según el artículo 76.5. Ley reguladora de la Jurisdicción Social. «La Inspección de Trabajo y Seguridad Social y, en su caso, la Administración laboral, en el ejercicio de sus funciones, cuando el centro de trabajo sometido a inspección coincidiese con el domicilio de la persona afectada, podrá solicitar la correspondiente autorización judicial, si el titular se opusiere o existiese riesgo de tal oposición, en relación con los procedimientos administrativos de los que conozca o pueda conocer posteriormente la jurisdicción social, o para posibilitar cualquier otra medida de inspección o control que pudiera afectar a derechos fundamentales o libertades públicas.». Ley 29/1998, de 13 de julio, reguladora de la Jurisdicción contencioso-administrativa. artículo 8.6: «Conocerán también los Juzgados de lo Contencioso-administrativo de las autorizaciones para la entrada en domicilios y restantes lugares cuyo acceso requiera el consentimiento de su titular, siempre que ello proceda para la ejecución forzosa de actos de la Administración pública.». Precepto que debe considerarse extensivo a los actos de investigación o inspección (STC de 23 de febrero).

37 El artículo 18. 1 CE precisa dentro del concepto estricto de vida privada los derechos al honor, la intimidad personal y familiar y a la propia imagen. Estos derechos derivan de la dignidad de la persona y el objetivo de su reconocimiento consiste en garantizar al individuo un poder jurídico sobre la información personal y familiar, si bien con los límites de los restantes derechos fundamentales y bienes jurídicos constitucionalmente protegidos. De acuerdo con la jurisprudencia del TC (STC de 12 de noviembre), el derecho al honor, a la intimidad familiar y personal —incluyendo la corporal- constituye un derecho intangible cuyo núcleo esencial en sociedades pluralistas ideológicamente heterogéneas deben determinar los tribunales.

38 ATC de 26 de marzo: «...ello no impide que, atendiendo a las circunstancias de cada caso, que el Juez debe ponderar..., pueda autorizarse la entrada en el domicilio sin previo aviso de su titular». 
carácter de excepcional, el auto que autorice la entrada, debe ser motivado, y, además, en base al principio de proporcionalidad, señalar (aparte de identificar debidamente el domicilio y su titular), las circunstancias de la entrada y registro, es decir, ha de consignarse el contenido de la actuación a practicar, esto es, el tiempo señalado al efecto (día o días concretos), objeto (recoger documentación, etc.) e, incluso, número de personas ${ }^{39}$.

Como ya hemos tratado anteriormente, insistimos en que la articulación de unos medios de control y el ejercicio de estos por parte de la Inspección de Trabajo se encuentra fuertemente limitada al concurrir diversos derechos que deben ser protegidos. Pero considero que, la empleada de hogar como ciudadana que, es tiene derecho a la integridad física y moral (artículo $15 \mathrm{CE}$ ), por lo que deberá reconsiderarse cómo facilitar a la Inspección de Trabajo el modo de comprobar que se está cumpliendo con lo establecido legalmente.

\section{Dignificar el trabajo doméstico exige de la ratificación del convenio 189 de la OIT}

Para la Organización Internacional del Trabajo «discriminar en el empleo y la ocupación es tratar a las personas de forma diferente y menos favorable debido a determinadas características como el sexo, el color de la piel, su religión, ideas políticas u origen social, con independencia de los requerimientos del trabajo». El artículo 1.a de la Convención sobre Discriminación en el empleo y la ocupación de 1958 define la discriminación como «cualquier distinción, exclusión o preferencia realizada en base a la raza, color, sexo, religión, opinión política, nacionalidad u origen social, que tiene el efecto de anular o perjudicar la igualdad de oportunidades y tratamiento en el empleo u ocupación».

La doctrina científica española ha recibido la aprobación del Convenio Colectivo número 189 y la Recomendación 201 de la OIT frente a las discriminaciones laborales del trabajo doméstico "un hecho histórico», como «una conquista social» (Quesada, 2011: 1), o como «un punto de inflexión» (Vela, 2017: 283), mediante el cual la OIT «integra a estos trabajadores dentro de su objetivo fundamental de trabajo decente» (Romeral, 2013: 2).

$Y$ es que la ratificación del convenio aseguraría en una pequeña recapitulación, la libertad sindical y el derecho a la negociación colectiva (artículo 3/2), la

39 Según la jurisprudencia del Tribunal Europeo de Derechos Humanos, desde los casos Chappelll y Niemietz (Sentencias de TEDH de 30 de marzo de 1989 y de 16 de diciembre de 1992) han de limitarse, entre otros extremos, el período de duración y el tiempo de entrada, así como el número de personas que puedan acceder al domicilio, aun cuando no se identifiquen individualmente con carácter previo: vid STC 50/1995 citada, F.J. 7. ${ }^{\circ}$ 
realización de inspecciones de trabajo eficaces (artículo 5/10/17), en las que se controle el debido cumplimiento de lo estipulado en el Régimen de trabajo, el derecho a recibir una información adecuada y verificable sobre su trabajo y sus empleadores/as (artículo 7), el control sobre las prácticas abusivas de las agencias de colocación (artículo 15), la no discriminación por motivos de sexo [género], (artículo 11), la eliminación de todo tipo de abuso en las relaciones laborales (Grau, 2019: 47), la edad mínima de entada al trabajo (artículo 4),y finalmente la demandada equiparación al Régimen General de Seguridad Social (Art, 14). El gobierno actual, ha decidido no ratificar de momento dicho convenio, alegando como impedimento principal, la intervención dentro de los hogares, a sabiendas de las nuevas propuestas para ejercer estas inspecciones, la dificultad de regular las relaciones de salud y bienestar de estos para impedir riesgos laborales y de introducir la prestación de desempleo.

El derecho a un entorno de trabajo seguro y saludable, aunque las medidas para su garantía se podrán adaptar poco a poco en consulta con las organizaciones representativas de los empleadores y de los trabajadores (artículo 13 Convenio). Tales medidas (Recomendación, numeral 19) se destinan a eliminar o reducir al límite, en cuanto sea posible, los peligros y riesgos afines con el trabajo, al disponer un régimen de inspección con sanciones adecuadas, a confeccionar y posteriormente publicar estadísticas sobre enfermedades y accidentes en el trabajo doméstico, a prestar orientación en materia de seguridad y salud en el trabajo, comprendiendo los aspectos ergonómicos y mecanismos para protección, al mismo tiempo que la posibilidad de realizar programas para realizar formación.

Finalmente, la protección en materia de salud y seguridad laboral es un derecho de toda persona del que ninguna puede ser desprovista. La especificidad real de la naturaleza de sus empleadores, que no son empresas sino particulares sin las obligaciones preventivas complejas que la ley establece para las empresas, no significa que no tengan que velar porque el trabajo se realice en condiciones seguras. Tampoco las dificultades para la función inspectora, al no poder la Inspección de Trabajo entrar en un domicilio como sí puede hacerlo en los locales de una empresa, pueden impedir que la labor inspectora se realice. Estas especificidades aconsejan instrumentar mecanismos específicos y practicables para garantizar el derecho a un trabajo seguro y saludable y a la integridad psico-física de las personas empleadas en los hogares (Martínez, 2020: 31-32), pero nunca una excusa para eludir ese derecho.

\section{Reflexiones finales}

Es un hecho, que las mujeres soportan en mayor medida el peso del «empleo informal», muy asociada a actividades muy feminizadas; padecen mayores 
porcentajes de exclusión laboral, ocupan trabajos menos cualificados y en general realizan su actividad en sectores menos estructurados y con mayor índice de precariedad.

Otro dato importante, es el aislamiento en que se produce el trabajo al servicio del hogar familiar. En muchos casos existe un único trabajador doméstico en el hogar familiar, y, en muchas ocasiones también, su actividad se realiza sola, sin compañía de quienes conviven en el hogar familiar.

Hay que recordar las restricciones que la Constitución establece en cuanto a las posibilidades de control de las actividades que se realizan en el hogar familiar, con las consiguientes consecuencias en materia de prevención de riesgos laborales.

Resulta necesaria la modulación de los derechos de ambas partes, especialmente de los laborales, ya que son, las personas trabajadoras las que se acaban subordinando y sometiendo de un modo realmente descompensado a favor de los derechos e intereses del empleador, más allá de lo necesario o justificado.

Los riesgos de esta actividad son idénticos a los que puede sufrir cualquier otro trabajador que la realice. A este respecto el legislador puede exigir al titular del hogar familiar el establecimiento de unas mínimas medidas necesarias para preservar la seguridad y salud de su empleado, al igual que se hace cuando el trabajo se presta por un trabajador de los protegidos por la Ley, por ejemplo, las previstas para el que realiza un jardinero, un chófer, un cocinero, o el personal de limpieza de un hotel, una residencia o un hospital. El trabajo es el mismo y las medidas preventivas también deberían serlo.

Velar por la salud laboral en este colectivo supone un reto en prevención de riesgos laborales, no sólo en lo que a factores tradicionales de riesgo se refiere sino por la exposición a otros factores de riesgo de tipo psicosocial (consideración de las jornadas de trabajo, régimen de descansos de especial importancia en situación de interinas, estrés y ansiedad por situaciones de pluriempleo, situaciones de acoso sexual, abusos...).

Nada impide que se establezcan un conjunto de previsiones básicas en cuanto a salubridad, intimidad personal, vigilancia de la salud, evaluación de riesgos, formación e información de estos trabajadores sobre los riesgos de su trabajo y del espacio donde lo desarrolla, el modo de ejecutarlo, las medidas preventivas que tienen que adoptarse, y las infracciones y sanciones derivadas de su incumplimiento.

El establecimiento de estas medidas demandaría unos mínimos conocimientos y una inversión económica que se incrementaría en el supuesto de acudir a terceras personas para evaluar los riegos, formar al trabajador y adoptar las medidas preventivas. 
Desde la perspectiva de la prevención de riegos, que el titular del hogar familiar no esté dispuesto a asumir estos gastos, no parece admisible, como tampoco puede justificar la opción del legislador de excluir a esta relación laboral especial de la norma.

La ratificación por España del Convenio 189, aunque por sí misma no obligaría a cambios normativos inmediatos, sí debería ser el pistoletazo de salida para establecer un programa de actuación, con compromisos políticos y presupuestarios, para abordar, en plazo razonable, la reforma en lo quesea necesario de la normativa, y su efectiva implementación.

Dicha ratificación goza de un gran consenso social y político. Viene siendo reiteradamente demandada por los sindicatos, los colectivos de empleadas domésticas y las organizaciones feministas. Ha recibido también un amplísimo asentimiento parlamentario favorable en diversas ocasiones. El presidente del Gobierno y las ministras de Trabajo y de Igualdad han anunciado su compromiso de ratificarlo. Hacerlo contribuirá a corregir los déficits señalados y representa una oportunidad para avanzar en la justicia social y el trabajo decente para las empleadas del hogar y para toda la sociedad.

\section{Bibliografía}

Alonso De Antonio, Ángel Luis (1993) El derecho a la inviolabilidad domiciliaria en la Constitución española de 1978. Madrid. Ed. COLEX.

Ayala Del Pino, Cristina (2007) «La prevención de riesgos laborales en la relación laboral especial del servicio del hogar familiar", Saberes, Revista de estudios jurídicos, económicos y sociales, vol. 5 .

Cabeza Pereiro, Jaime (2019) «El trabajo doméstico en la normativa de la OIT». Trabajo y derecho: nueva revista de actualidad y relaciones laborales, N. ${ }^{\circ}$ Extra 9.

Cabezuelo Arenas, Ana Laura (1998) en Derecho a la intimidad, Ed. Tirant lo Blanch, Valencia.

Cardenal Montraveta, Sergi y Cardenal Alemany, Felipe (2002) «El delito contra los derechos de los trabajadores extranjeros sin permiso de trabajo: art. 312.2 in fine Cp. especial referencia a su aplicación jurisprudencial», Revista del Poder Judicial, núm. 66. Madrid.

Conde-Pumpido Tourón, Cándido (2003) Cuadernos de derecho judicial, N.o. 4 (Ejemplar dedicado a: Extranjeros y derecho penal / José Antonio Martín Pallín (dir.)).

Cospedal García, María Dolores (1999) «Delitos contra los derechos de los trabajadores», Revista del Ministerio Fiscal, núm. 6, Ministerio de Justicia.

De Dios Castro, B. (2015) Guía de prevención de riesgos laborales: empleadas del hogar. Aranzadi.

De La Villa Gil, Luis Enrique (1985) «La relación laboral de carácter especial del Servicio del Hogar Familiar», Documentación Laboral, número monográfico.

Derecho de la prevención de riesgos laborales (2010) Ed. Tirant lo Blanch.

Desdentado Daroca, Eva (2016) «Las reformas de la regulación del trabajo doméstico por cuenta ajena en España». Investigaciones Feministas 129. Vol. 7 Núm 1. 
Doyal, Len (1991) «Riesgos para la salud en el entorno doméstico: un marco conceptual», Mujer, salud y trabajo/Documento, Quadern CAPS, núm. 121.

Fernández Marcos, Leodegario (1996) Comentarios a la Ley de Prevención de Riesgos Laborales, Ed. Dykinson, Madrid.

García Blasco, Juan, González Labrada, Manuel y Cardenal Carro, Miguel (2001) Derecho de la Seguridad y Salud en el trabajo, Madrid, Civitas.

García Galverde, María Dolores y García Valverde, Facundo (2005) «La seguridad y salud laboral en el servicio del hogar familiar. El juego de la normativa civil y penal», Revista de Derecho Privado, núm. 11.

Garcia Valverde, María Dolores (1995) «Una exclusión «particular» de la Ley de prevención de riesgos laborales: el servicio del hogar familiar, Ley de Prevención de Riesgos Laborales». (Coord.) R., Escudero RodríGuez. XIV Jornadas Universitarias Andaluzas de Derecho del Trabajo y Relaciones Laborales, Málaga, Consejo Andaluz de Relaciones Laborales.

GARrigues GimÉnez, Amparo (1997): «Algunos aspectos preliminares en torno a la Ley de Prevención de Riesgos Laborales», Lección 1. a, en AA.VV., Lecciones sobre la Ley de Prevención de Riesgos Laborales, (Dir.) J. I., García Ninet, Universitat Jaume I, Castelló de la Plana.

González Ortega, Santiago y Aparicio Tovar, Joaquin (1996) Comentarios a la Ley 31/1995, de Prevención de Riesgos Laborales, Trotta, Madrid.

González-Carvajal García, Juan Manuel (2000) Aspectos Jurídico Públicos de la Prevención de Riesgos Laborales. Ed. Colex. 2000.

Grau Pineda, Carmen (2019) «De sirvientas a trabajadoras: la necesaria ratificación del Convenio 189 OIT sobre trabajo decente para las trabajadoras y los trabajadores domésticos». Lex Social, vol. 9, núm. 2.

Gonzaléz Hernández, Guadalupe (1989) Relaciones laborales especiales, Il Ilustre Consell General de Collegis de Graduats Socials de Catalunya, Mapfre Mutua Patronal, Barcelona, Vol. I.

Igartua Miró, María Teresa (2018), Sistema de prevención de riesgos laborales, Ed.Tecnos.

López Cumbre, Lourdes (2000) «La relación especial del servicio del hogar familiar, El estatuto de los Trabajadores, 20 años después», REDT, núm. 100.

López Gandía, Juan y Toscani Giménez, Daniel (2006) Los trabajadores al servicio del hogar familiar. Aspectos laborales y de Seguridad Social. Propuestas de Reforma, Albacete, Bomarzo.

López Јасов, M. ${ }^{a}$ Jesús (2014) Salud laboral: conceptos y técnicas para la prevención de riesgos laborales / Carlos Ruiz Frutos (aut.), Jordi Delclòs (aut.), Ana M. García García (aut.), Elena Ronda Pérez (aut.), Fernando G. Benavides (aut.).

Lousada Arochena, José Fernando (2018) «Normativa Internacional contra la explotación humana y laboral en el trabajo doméstico: la ONU y la OIT». Lan Harremanak N. 39.

Martínez Arranz, Sonia (2020) Prevención de riesgos laborales en el sector del empleo doméstico: actividad física, entrenamiento mental y emocional como técnicas preventivas. Reflexiones sobre el empleo doméstico: de dónde venimos, dónde nos encontramos y hacia dónde vamos.

Montoya Melgar, Alfredo y Piza Granados, Jaime (1996), Curso de Seguridad y Salud en el Trabajo, Ed. Mc Graw-Hill.

Moreno Cáliz, Susana y Marín Albá, S. (2004), «Aplicación y control de la normativa de prevención en los domicilios particulares». $A S$ núm. 10 (Estudio). 
Nieto Rojas, Patricia (2019) «Trabajo doméstico y derechos colectivos, algunas reflexiones al hilo del RD 1620/2011 y del Convenio 189 OIT». Lex Social. Vol. 9 n. ${ }^{\circ} 2$.

Pérez De Los Cobos Orinuel, Francisco (1991) «La Directiva marco sobre medidas de seguridad y salud de los trabajadores en el trabajo y la adaptación del Ordenamiento español», Relaciones Laborales, número 8.

Pérez Orozco, Amaia y López GiL, S. (2016) Desigualdades a flor de piel: cadenas globales de cuidados. Concreciones en el empleo de hogar y articulaciones politicas. s.l. ONU Mujeres.

Quesada Segura, Rosa (2011) "La dignificación del trabajo doméstico. El Convenio n.o 189 OIT, 2011", Revista General de Derecho del Trabajo y de la Seguridad Social-Iustel, número 27.

Ramírez Martínez, Juan Manuel (1998) «La relación especial de trabajo al servicio del hogar familiar (RD 1424/85 de 1 de agosto)», $A L$, Vol. I, 1986.

Rodríguez-INIESTA, G. "El trabajo en el hogar no precisa esfuerzos (titular tomado del diario El País, viernes, 5 de febrero de 1999). En torno a la STSJ del País Vasco de 29 de septiembre de 1998", $A S$, ref. 81, T. IV.

RodRíGUEZ-INIESTA, Guillermo (2012) «Ante incumplimientos empresariales del empleador doméstico (afiliación, alta y cotización) ¿cabe exigirle responsabilidad prestacional por contingencias profesionales?», en La Responsabilidad del empresario, IX Congreso de la Asociación Española de Salud y Seguridad Social, Murcia, Ed. Laborum.

Romeral Hernández, Josefa (2013) «El impacto del Convenio 189 de la OIT en las condiciones de trabajo de los empleados de hogar», Aranzadi Social, número 7.

Sala Franco, Tomás (2010) Derecho de la prevención de riesgos laborales, Ed. Tirant lo Blanch.

Sala Franco, Tomás (1986) «La relación laboral especial del servicio del hogar familiar y el contrato de trabajo doméstico», $R L$, T. I, núm. 4.

Salcedo Beltrán, María Del Carmen (2020) El trabajo doméstico en España: planteamientos y desafíos insoslayables frente a la "esclavitud moderna». Revista General de Derecho del Trabajo y de la Seguridad Social, N. ${ }^{\circ} 55$.

Sánchez Cubel, Dolores (1996) Todo sobre la nueva ley de prevención de riesgos laborales, Ed. Praxis.

SANZ SÁEZ, Concepción «Derechos colectivos y empleadas del hogar: reformas jurídicas inaplazables para un trabajo decente del trabajo doméstico en España». https://www. ccoo.es/99d7ae8ee035fef57c16d423f2cb62eb000001.pdf.

Schneider De Villegas, G. (1990), «Trabajadores a domicilio: Necesidad de una protección especial», RIT, Vol., 109, núm. 3.

Sempere Navarro, Antonio Vicente, García Blasco, Juan, González Labrada, Manuel, Torada, Rebeca y Moreno, N. (2001) «Salud laboral y género», VV. AA. (Coord. Durán, M. ${ }^{a}$ Ángeles), Mujer y trabajo. Problemática actual, Ed. Germania.

- Sistema de prevención de riesgos laborales, Ed. Tecnos, 2008, pág. 68.

Vela Díaz, Raquel (2017) «La promoción internacional de un trabajo decente para las personas empleadas de hogar: el Convenio 189 de la OIT sobre los trabajadores domésticos», Revista del Ministerio de Empleo y Seguridad Social-Derecho Social Internacional y Comunitario, número 127.

VV.AA (I987) Comentarios a las leyes laborales. El Estatuto de los Trabajadores, dirigidos por Borrajo Dacruz, Efrén, EDERSA, Madrid, T. II, Vol. II.

VV.AA, (2008), Comentarios a la Ley de prevención de riesgos laborales (Coord. M. IGLESIAS Cabrero)- Ed. Civitas.

VV.AA.(I997), Lecciones sobre la Ley de Prevención de Riesgos Laborales (Dir. J.I García Ninet) Castellón. 